\title{
BIOMASS DISTRIBUTION IN FRESHWATER PLANKTON COMMUNITIES
}

\author{
Paul A. del Giorgio and Josep M. Gasol* \\ Department of Biology, McGill University, 1205 Dr. Penfield, Montreal, Québec H3A 1B1, Canada
}

Submitted January 25, 1993; Revised August 25, 1994; Accepted September 28, 1994

\begin{abstract}
Both resource control of heterotrophic biomass and heterotrophic regulation of plant populations imply that heterotrophic biomass should constitute an increasingly smaller proportion of total system biomass as the turnover time of autotrophs increases. Although this trend is widely accepted, it has seldom been tested, perhaps because comparable data for many ecosystems are hard to collect. The plankton are an exception to this difficulty. Because the biomasses of both autotrophs and heterotrophs can be estimated with relative ease and because workers use similar techniques, data are available from a wide range of lakes. Both literature data, representing a wide geographical range, and data from a localized set of lakes show that the ratio of heterotrophic to autotrophic biomass ( $H / A$ ratio) is well above unity where autotrophic biomass is low and declines where autotrophic biomass is high. A similar pattern is found in marine and terrestrial systems. In terrestrial systems, this pattern has been explained by changes in the turnover time of the autotrophic biomass, but in lakes energetic subsidies from the littoral and the watershed are likely needed to support the relatively high heterotrophic biomass of many oligotrophic systems.
\end{abstract}

One of the oldest and most important paradigms in ecology suggests that biomass is usually distributed as a pyramid (Elton 1927), where a broad autotrophic base supports successively smaller strata of heterotrophs (Odum 1971; Wetzel 1983), although inverted biomass pyramids may occur where the autotrophic base has a high rate of turnover (Odum 1971). The paradigm of biomass distribution still stands as one of the pillars of ecology and appears under various formulations in many ecological textbooks (Odum 1971; Whittaker 1975; Hutchinson 1978; Ricklefs 1979; Wetzel 1983). Its widespread use in ecological theory, however, is in marked contrast with the paucity of data to support it. Relatively few authors have described biomass distribution into autotrophic and heterotrophic components across ecosystems (see, e.g., Whittaker and Likens 1973; O'Neill 1976; O'Neill and DeAngelis 1981), and no general model has been quantified.

The distribution of biomass into autotrophs and heterotrophs has traditionally been linked to the turnover of the primary producers (Odum 1971). O'Neill and DeAngelis (1981) hypothesized that the ratio of total heterotrophic to autotrophic biomass $(H / A$ ratio) should be highest in the systems with the most rapid turnover of the autotrophic base, because increased regulation is needed where the poten-

\footnotetext{
* Present address: Institut de Ciències del Mar, Passeig Joan de Borbó, s/n, E-08039 Barcelona, Spain.
} 
tial for exhausting limiting nutrient resources is greatest. This view is also consistent with resource control of heterotrophs (McCauley et al. 1988), because autotrophic populations that have high specific production rates are able to support higher relative heterotrophic biomass. Both approaches suggest that there should be a declining trend in the $H / A$ ratio along a broad axis of decreasing plant turnover rate, from phytoplankton communities (characterized by relatively high turnover rates), to grasslands, to forests (often characterized by extremely low turnover of the plant biomass). This axis also represents a systematic increase in plant biomass and productivity, so over a broad range the $H / A$ ratio should be inversely related to both primary production and biomass. This pattern across a broad range of ecosystem types with widely different primary productivity, plant biomass, and turnover rate has been empirically described before (O'Neill and DeAngelis 1981).

Although forests clearly differ from plankton communities in terms of the amount of heterotrophic biomass that is supported per unit of autotrophic biomass, it is not well understood whether the same trends should be expected when the analysis is circumscribed to increasingly smaller portions of the spectrum of natural primary productivity and plant biomass. Other factors, such as food web interactions, may increasingly swamp the effect of differences in turnover rate of autotrophs. Among plankton communities, for example, autotrophic biomass, production, and turnover rate may vary by orders of magnitude, and yet it is not known whether the shape of the biomass pyramid remains constant or whether it varies systematically along any of these axes. The regulation of planktonic biomass along gradients of enrichment has been a matter of debate for years, and plankton communities have often been used as model systems to test theories of consumer foraging. Proponents of resource or bottom-up regulation argue that both autotrophic and heterotrophic biomasses are constrained by the availability of limiting resources (Power 1992). Proponents of top-down control, on the other hand, argue that higher trophic levels have the potential to limit the biomass of lower trophic levels, in which case resources become secondary as a regulating factor (Carpenter and Kitchell 1988). In turn, both bottom-up and top-down regulation are usually viewed within the context of two major theories that deal with the patterns in consumer foraging and functional responses that underlie trophic interactions within food webs. The more traditional prey-dependent theory assumes that the rate of consumption of prey by predator depends only on prey density (Oksanen et al. 1981; Fretwell 1987). Ratio-dependent theory, on the other hand, asserts that consumption of prey depends on the ratio of predator to prey (Arditi et al. 1991).

Prey- and ratio-dependent models suggest very different patterns of biomass distribution into heterotrophs and autotrophs along gradients of primary productivity within plankton communities. In ratio-dependent models, all trophic levels increase proportionately, which is a pattern similar to that expected from bottom-up regulation of producer and consumer biomass along gradients of enrichment. In prey-dependent models, the responses vary depending on the trophic level and the number of levels, and this pattern sets the basis for top-down control within food webs (Ginzburg and Akcakaya 1992). Large-scale empirical comparisons designed to test these contrasting hypotheses are lacking, and plankton communities are particularly well suited to explore these questions. The biomass 
of both autotrophs and heterotrophs can be estimated with relative ease, and researchers use similar methods, so there is a wealth of published data on a wide variety of lakes that can be compared.

In this article, we use the total biomasses of auto- and heterotrophic plankton to test the hypothesis that the $H / A$ ratio declines systematically along gradients of increasing nutrient enrichment and autotrophic biomass in lakes. In the se systems, rates of phytoplankton production are strongly correlated to algal biomass and the concentration of chlorophyll (Smith 1979; del Giorgio and Peters 1993), so this gradient of autotrophic biomass also corresponds to a productivity gradient. We use both data extracted from the literature, representing a wide geographical range, and actual measurements of planktonic biomass from a localized set of lakes in southern Québec. We then question whether changes in the relative contribution of autotrophs and heterotrophs are consistent with changes in resource availability along trophic gradients (bottom-up) or may result from trophic interactions within food webs (top-down). We attempt to incorporate the entire resource base of the plankton by analyzing the biomass distribution into planktonic autotrophs and heterotrophs along gradients of both nutrient enrichment and external carbon inputs to lakes. Finally, we compare trends in freshwater pelagic communities with other ecosystems to establish the generality of this pattern.

\section{DATA COLLECTION}

\section{Field Data}

Plankton biomass and related parameters were sampled along the growing season in 18 southern Québec lakes, selected to span 1.5 orders of magnitude in total phosphorus (TP) and chlorophyll $a$ (CHL); these lakes vary threefold in dissolved organic carbon concentration (DOC). The morphometry of the lakes is also varied: the mean depth ranges from 4 to $80 \mathrm{~m}$, and the surface area from 0.8 to $90 \mathrm{~km}^{2}$. The lakes were sampled monthly from May to September 1990 . After determining the thermal profile, a diaphragm pump was used to collect water from the entire epilimnion and the upper half of the metalimnion. The total numbers of bacteria, microzooplankton (nanoflagellates, ciliates, rotifers), and macrozooplankton (crustacean zooplankton and larger ciliates), together with their size, were determined for each sample. Conversion factors given by Bjørnsen (1986) for bacteria, Børsheim and Bratbak (1987) for flagellates, Gates et al. (1982) for ciliates, and McCauley (1984) for zooplankton were used to transform these densities to biomass estimates. Total heterotrophic biomass is the sum of the biomasses of these components. Details of sampling, counting, and biomass calculation for each of the heterotrophic components are given elsewhere (del Giorgio 1994). Phytoplankton biomass was not measured directly but rather calculated from the measured chlorophyll $a$ concentration, using a conversion factor of $40 \mathrm{mg} \mathrm{C}$ per $\mathrm{mg}$ CHL. The potential bias in the calculation of biomass from chlorophyll was assessed by independently calculating phytoplankton biomass (in $\mathrm{mg} \mathrm{ww} \mathrm{L}^{-1}$ ) from total phosphorus, using the empirical equation that Watson and Kalff (1981) 
TABLE 1

Summer Average (geometric mean) Values for the Lakes Sampled in Southern Québec DURING I990

\begin{tabular}{|c|c|c|c|c|c|c|c|c|c|}
\hline Lake & $\begin{array}{c}\text { DOC } \\
\left(\mathrm{mg} \mathrm{C}^{-1}\right)\end{array}$ & $\begin{array}{c}\text { TP } \\
(\mu \mathrm{g} \\
\left.\mathrm{L}^{-1}\right)\end{array}$ & $\begin{array}{c}\text { CHL } \\
(\mu \mathrm{g} \\
\left.\mathrm{L}^{-1}\right)\end{array}$ & $\begin{array}{c}\text { Algae } 1 \\
(\mu g C \\
\left.L^{-1}\right)\end{array}$ & $\begin{array}{c}\text { Algae } 2 \\
(\mu g \mathrm{C} \\
\left.\mathrm{L}^{-1}\right)\end{array}$ & $\begin{array}{c}\text { Bacteria } \\
(\mu \mathrm{g} \mathrm{C} \\
\left.\mathrm{L}^{-1}\right)\end{array}$ & $\begin{array}{c}\mu \mathrm{ZP} \\
(\mu \mathrm{gCC} \\
\left.\mathrm{L}^{-1}\right)\end{array}$ & $\begin{array}{c}\text { MZP } \\
\left(\mu \mathrm{g} \mathrm{C}^{-1}\right) \\
\left.\mathrm{L}^{-1}\right)\end{array}$ & Ratio \\
\hline Aylmer & 5.61 & 10.82 & 2.26 & 90.40 & 134.59 & 12.87 & 12.41 & 5.69 & .34 \\
\hline Bowker & 2.51 & 4.65 & .86 & 34.40 & 41.32 & 8.32 & 6.01 & 10.88 & .73 \\
\hline Brome & 3.35 & 10.27 & 3.18 & 127.20 & 125.13 & 23.58 & 16.70 & 17.04 & .45 \\
\hline Connelly & 4.52 & 7.72 & 2.81 & 112.40 & 83.88 & 9.53 & 15.50 & 12.11 & .33 \\
\hline Coulombe & 7.00 & 10.44 & 3.67 & 146.80 & 128.03 & 12.82 & 20.84 & 14.66 & .33 \\
\hline Croche & 4.52 & 4.56 & 1.87 & 72.00 & 40.21 & 7.80 & 23.84 & 14.87 & .64 \\
\hline Cromwell & 7.53 & 9.77 & 5.16 & 206.40 & 116.74 & 8.35 & 21.66 & 13.62 & .21 \\
\hline D'Argent & 5.04 & 9.89 & 3.25 & 130.00 & 118.72 & 18.72 & 17.68 & 14.62 & .39 \\
\hline Fitch Bay & 3.80 & 9.80 & 3.41 & 136.40 & 117.21 & 12.75 & 31.06 & 17.36 & .45 \\
\hline L'Achigan & 3.87 & 6.41 & 1.72 & 68.80 & 64.69 & 7.53 & 6.60 & 20.14 & .50 \\
\hline Lovering & 5.50 & 7.93 & 2.18 & 87.20 & 87.15 & 8.93 & 13.71 & 9.38 & .37 \\
\hline Magog & 4.00 & 16.51 & 5.45 & 218.00 & 243.25 & 21.26 & 31.80 & 37.40 & .41 \\
\hline Nicolet & 2.93 & 4.04 & 1.16 & 46.40 & 33.88 & 7.63 & 5.86 & 5.00 & .40 \\
\hline Quinn Bay & 3.74 & 10.60 & 3.94 & 157.60 & 130.81 & 9.74 & 31.73 & 7.16 & .31 \\
\hline Silver & 2.73 & 6.94 & 2.33 & 93.60 & 72.36 & 12.82 & 9.25 & 6.17 & .30 \\
\hline South Bay & 3.90 & 15.30 & 3.94 & 157.60 & 218.66 & 31.32 & 50.61 & 13.91 & .61 \\
\hline Stukely & 3.76 & 5.50 & .96 & 38.40 & 52.22 & 8.25 & 4.68 & 14.60 & .72 \\
\hline Waterloo & 5.11 & 33.17 & 13.15 & 526.00 & 645.95 & 37.82 & 33.99 & 65.74 & .26 \\
\hline
\end{tabular}

NotE.-Fitch Bay, Quinn Bay, and South Bay are different basins of Lake Memphremagog. DOC, Dissolved organic carbon; TP, total phosphorus; CHL, chlorophyll $a$; algae 1, phytoplankton biomass calculated from chlorophyll; algae 2, phytoplankton biomass calculated from total phosphorus; $\mu \mathrm{ZP}$, microzooplankton biomass, including heterotrophic protists (flagellates and ciliates), rotifers, and nauplii; MZP, macrozooplankton biomass (crustaceans); Ratio, ratio of total heterotrophic to total autotrophic biomass ( $H / A$ ratio) using the algae 1 biomass estimate.

developed for this same set of Québec lakes (table 1). The two approaches were compared in the sampled lakes, when the appropriate data were available.

\section{Literature Data}

Overall 47 simultaneous estimates of bacterial, zooplankton, and algal biomass were collected from the literature, which represents one to several years for 39 lakes worldwide. The complete literature data set is available from the authors or from the Repository of Unpublished Data (CISTI, National Research Council of Canada, Ottawa, Ontario K1A 0S2, Canada). Areal and volumetric biomass estimates were treated separately, to avoid interconversion errors. We tried to select studies that used comparable methods, but the data are inevitably heterogeneous. For example, algal picoplankton biomass was estimated in 21 lakes, heterotrophic protists were quantified in seven, and phototrophic sulfur bacteria biomass was estimated for one lake. When available, we accepted the conversion factors from biovolume to carbon employed by the different authors. When necessary, we converted from dry to wet weight using a factor of 0.1 , and from dry weight to carbon using a factor of 0.4 (MćCauley 1984). 


\section{Datà Analyses}

Data were $\log _{10}$ transformed prior to all statistical analyses, to stabilize the variance and attain homoscedasticity. We used the linear regression module of the SYSTAT software (Wilkinson 1987) to describe the statistical relationships, but since there is measurement error in both the dependent and independent variables, the Model II regression slope (Ricker 1973) is provided as an estimate of the functional relationship. Slopes were compared to the null hypothesis of equality to one using $t$-tests. Some of the relationships that appear in this article may involve spurious correlations (Prairie and Bird 1989), such as the relationship between the $H / A$ (heterotrophic/autotrophic biomass) ratio and chlorophyll or plant biomass. To avoid misinterpretation, our conclusions are directly drawn from the relationship between the two components of the ratio. For example, the $H / A$ ratio is said to decline with increasing algal biomass only when the slope of the relationship between total heterotrophic and autotrophic biomass is significantly less than one. These relations are nevertheless presented as ratios, because they make the point of interest most clearly.

\section{RESULTS AND DISCUSSION}

\section{The Decline of the H/A Ratio along Gradients of Enrichment}

The hypothesis that the $H / A$ ratio of freshwater plankton communities declines with increasing algal biomass is fully supported by our data. For the 39 literature lakes, total heterotrophic biomass increased less rapidly than autotrophic biomass across the trophic gradient of lakes (fig. 1). Heterotrophic biomass rose as autotrophic biomass to the 0.4 power, for both volumetric (fig. $1 A$ ) and areal data (fig. $1 B$ ). Literature data can contain collinearities that might result in spurious relationships associated with differences in sampling, locality, sampling method, analytical techniques, and so forth. However, if the pattern in figure $1 A$ and $B$ reflects collinearity, the Québec data (table 1), which are largely free of these potential problems, should be different. Yet the same pattern in planktonic biomass was seen there (fig. 1C): total heterotrophic biomass increased as autotrophic biomass to the 0.66 power, which is also significantly less than one (table 2 ) and not significantly different from the slopes of the literature data set $(P<.001)$.

When literature and field data are combined, the $H / A$ ratio decreased with increasing chlorophyll concentration, from 6.4 in unproductive lakes to 0.05 in extremely productive lakes (fig. 2). The Québec lakes represent a narrow portion of the entire spectrum of lakes in the data set but followed the same trend (fig. $2)$. The ratio decreased from oligotrophic lake Bowker $(H / A$ ratio $=0.73)$ to moderately eutrophic lakes Waterloo and Cromwell $(H / A$ ratios $=0.26$ and 0.21 , respectively). For both Québec and literature lakes, heterotrophic biomass increased less rapidly along a gradient of enrichment than autotrophic biomass. Overall, this pattern translated into a continuum from a totally inverted pyramid in ultraoligotrophic lakes to a classical pyramid with a very broad base in eutro- 

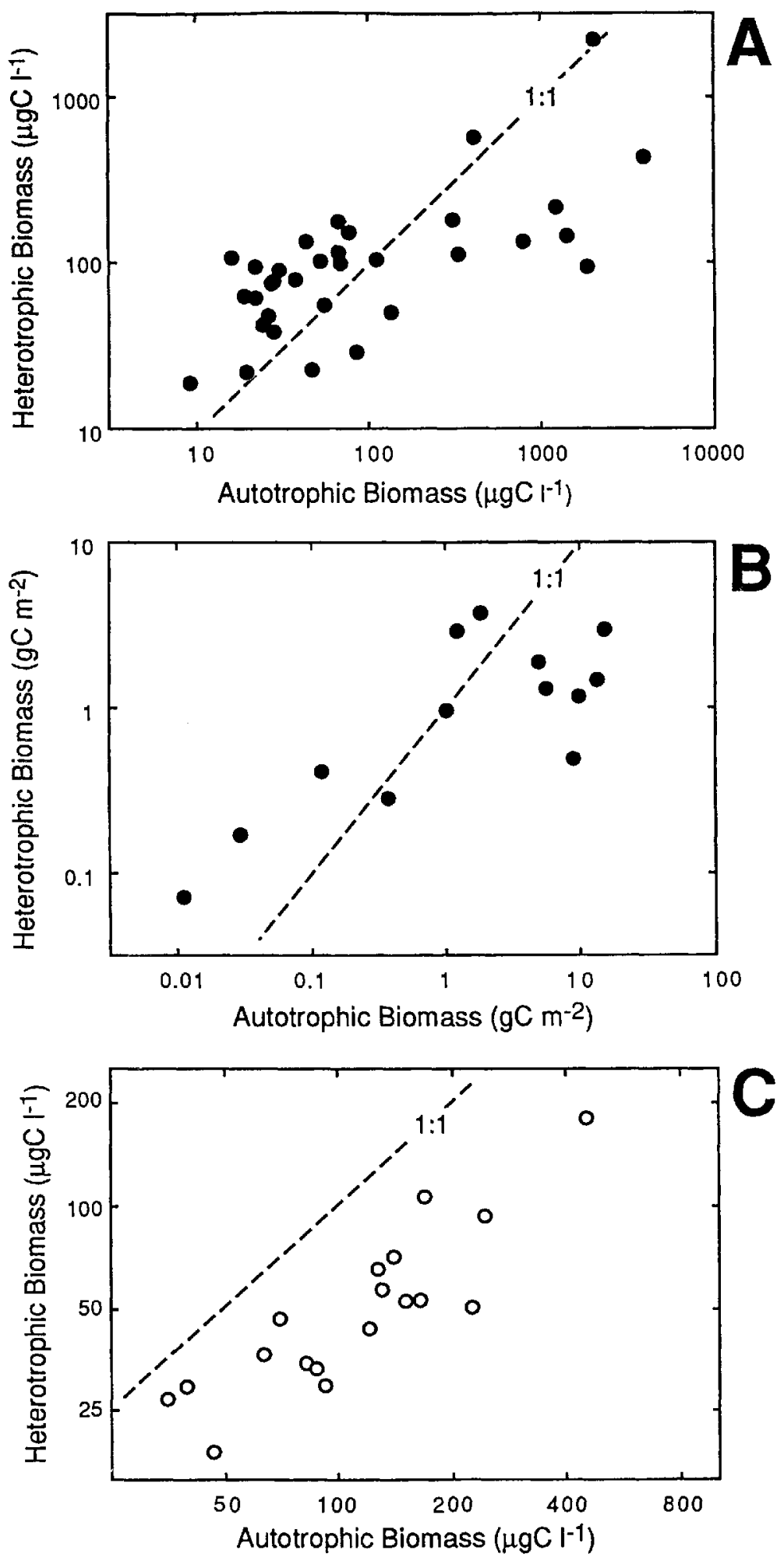

Fig. 1.-Relationship between total autotrophic biomass and total heterotrophic biomass for the lakes in the literature that presented data in volumetric $(A)$ or areal $(B)$ units and for the Québec lakes that we sampled $(C)$. The parameters for the linear regressions are in table 2 , and the Québec data are presented in table 1. Lines of equal biomass are presented. 


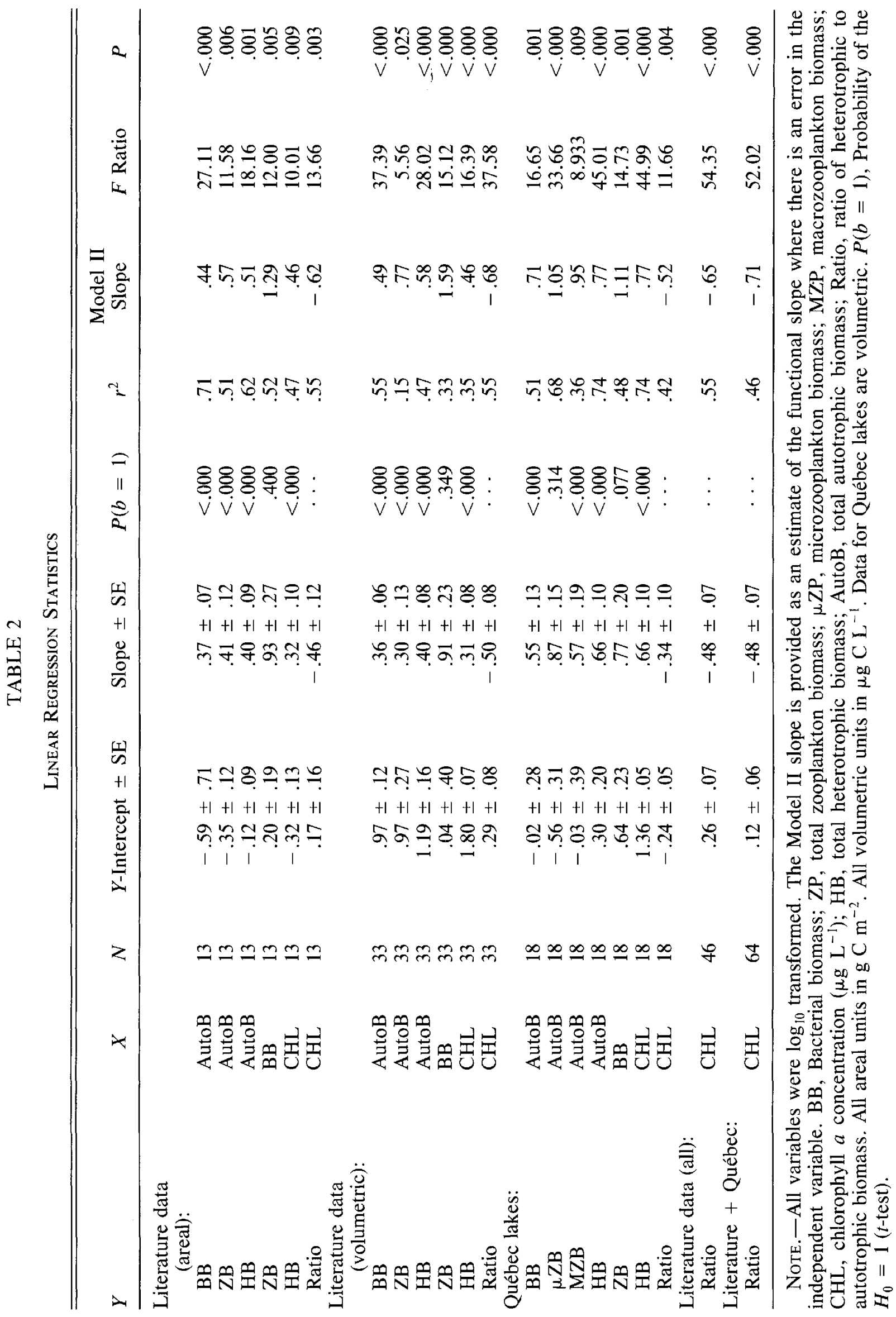




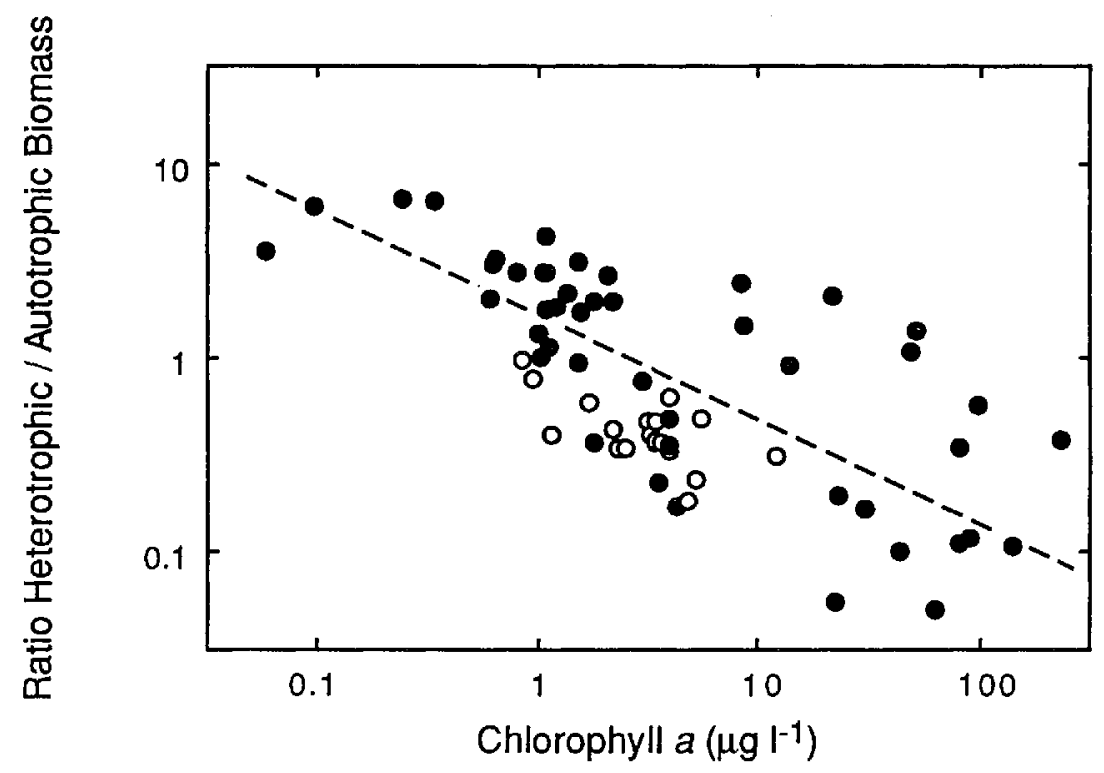

FIG. 2.-Ratio of heterotrophic to autotrophic biomass ( $H / A$ ratio) for the literature (solid circles) and Québec data (open circles), as a function of chlorophyll concentration. The line of best fit is shown, and the parameters of the equation are in table 2 .

phic lakes; intermediate states of approximately equal hetero- and autotrophic biomass occurred in lakes with around $2-5 \mathrm{mg}$ CHL $\mathrm{L}^{-1}$.

The Québec lakes tend to have lower $H / A$ ratios than the literature lakes at comparable chlorophyll concentrations (fig. 2). It is less likely that this difference is due to an underestimation of the heterotrophic biomass in our field data, because all the major heterotrophic components were carefully considered. Our use of a fixed conversion factor from chlorophyll to carbon, however, may have resulted in an overestimation of the autotrophic biomass in certain lakes and, therefore, in an underestimation of the $H / A$ ratio. A constant conversion factor assumes that the relationship between biomass and chlorophyll is constant among phytoplankton communities. Although chlorophyll to biomass ratios vary seasonally, with the physiological condition of the community, and among lakes (White et al. 1988), algal biomass and chlorophyll are correlated with a log-log slope of about one over a broad range of trophic states (OECD 1980, pp. 163-167; Vörös and Padisàk 1991). Therefore, the use of a constant ratio may increase the error but probably does not systematically bias the analysis. Nevertheless, we assessed the possible bias of estimating phytoplankton biomass from chlorophyll by independently calculating autotrophic biomass for the Québec lakes (table 1), using the empirical equation developed by Watson and Kalff (1981), who related phytoplankton biomass, estimated from biovolume, to total phosphorus. This equation is particularly appropriate for our data because it was derived for a set of lakes very similar to those sampled for the present study. The correspondence between total autotrophic biomass calculated from chlorophyll and from TP is good (table 1). Almost identical trends between the $H / A$ ratio and chlorophyll were obtained whether algal biomass was estimated from chlorophyll or from TP, which suggests that the patterns in $H / A$ ratios along gradients of enrichment are robust and not an artifact of the way autotrophic biomass was calculated. 


\section{Consumer Foraging and Plankton Biomass Distribution}

In the following section we compare the patterns in biomass distribution found in freshwater plankton communities with the predictions of prey-dependent and ratio-dependent theories of consumer foraging. Prey- and ratio-dependent models suggest different patterns of biomass along gradients of primary productivity. In ratio-dependent models, all trophic levels increase proportionately, whereas in prey-dependent models the responses vary depending on the trophic level and the number of levels (Ginzburg and Akçakaya 1992). A key test for the strength of trophic interactions was proposed by Mittelbach et al. (1988), who suggested that in systems that are primarily controlled by predators, resource and consumer densities should be uncorrelated where productivity varies and the number of significant trophic levels remains fixed. The Québec data set may be appropriate to assess this pattern, because most of the lakes we sampled contain herbivorous and carnivorous zooplankton, and planktivorous and piscivorous fish, and thus have broadly similar trophic structures and comparable numbers of trophic levels. Productivity, however, varies around 40 -fold across these lakes (del Giorgio and Peters 1994). Since, as shown above, consumer and producer biomasses are positively correlated, the data do not support the hypothesis of dominance of predator control in these systems.

It could be argued, however, that because there is no reference to the strength of these trophic links, in practice the number of effective trophic levels, or realized links, may vary (Power 1992). If this were the case, according to top-down theory we should expect either a pattern of stepwise increases in biomass (Oksanen et al. 1981) or major departures from the general trend in biomass distribution, which correspond to food webs predominantly regulated by predation control. None of these effects were observed, either in the narrow trophic span of the Québec lakes or in the much wider range of data from the literature, which encompasses a very heterogeneous set of lakes: consumer biomass increases continuously along gradients of increasing algal biomass and productivity in freshwater plankton communities. Moreover, both phytoplankton biomass and production increase continuously along gradients of nutrient enrichment, in the Québec lakes (del Giorgio and Peters 1994) and in a much wider trophic and geographical range (Smith 1979; del Giorgio and Peters 1993; Baines et al. 1994), a pattern that counters the predictions of top-down control (Fretwell 1987).

The lumping together of bacteria and herbivorous and predacious plankton in this analysis may present some difficulties, particularly in comparisons with other ecosystems. Although bacteria and other decomposers often comprise the bulk of heterotrophic biomass in many terrestrial ecosystems (Swift et al. 1979), these organisms have seldom been considered in formulations of predator-prey interactions and community control. In freshwater pelagic systems, bacteria cannot be ignored because these organisms are an integral part of planktonic food webs, and many consumers graze on both bacteria and phytoplankton indiscriminately (Sherr and Sherr 1988). An alternative way to view planktonic bacteria is not as consumers or decomposers but as producers of biomass. In higher plants, only some cells are photosynthetic, releasing dissolved organic matter into the phloem 

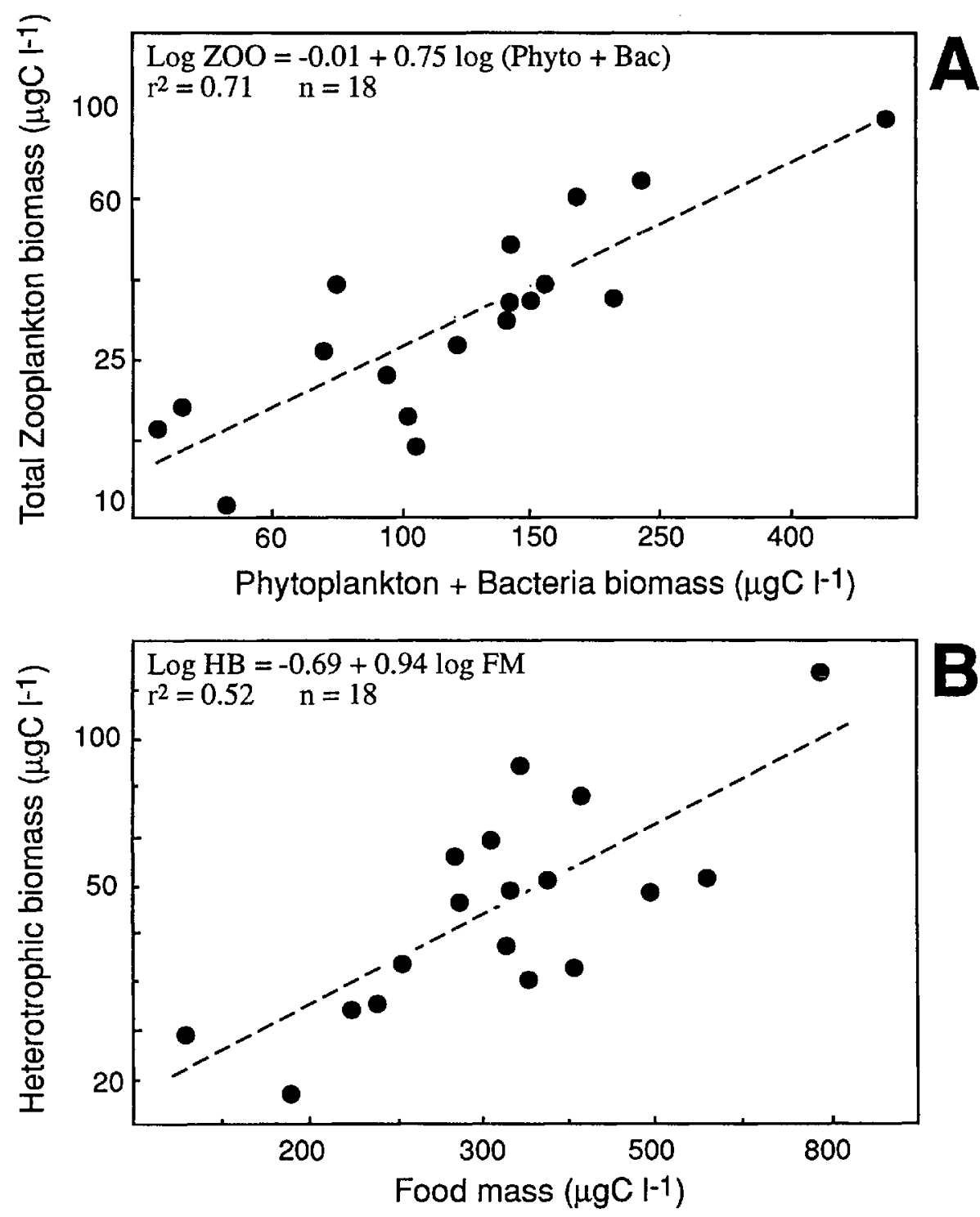

FIG. 3.-A, The relationship between total zooplankton biomass and the sum of phytoplankton and bacterial biomass for the Quebec lakes. The regression model and line of best fit are shown. $B$, The relationship between total heterotrophic biomass and total potential food base, calculated as the sum of phytoplankton biomass and the biologically labile fraction of the dissolved organic carbon pool, for the 18 lakes sampled in southern Québec. The regression model and line of best fit are shown.

to be used by other nonphotosynthetic cells, which function as heterotrophs. In strict analogy to higher plants, Flynn (1988) suggested that in aquatic systems bacteria should be considered "primary producers" because they use dissolved organic carbon produced by photosynthetic cells, both aquatic and terrestrial, and convert this carbon into biomass that is then available to consumers. From this alternative standpoint, bacteria should be placed with planktonic autotrophs, because together with phytoplankton, they compose the base of the food chain. Figure 3A shows the result of this analysis. Heterotrophic biomass, now the sum of micro- and macrozooplankton, is positively related to the sum of bacterial and phytoplankton carbon. The slope of this log-log relationship $(0.75)$ is still rather 
low, but it is not significantly different from unity $(P<.05)$, which suggests that planktonic primary and secondary consumers tend to approach an almost constant ratio in relation to their food supply, composed of both phytoplankton and bacteria. Whether bacteria are considered as consumers and included with the heterotrophic component or at the base of the food web and included with the autotrophic component, the conclusions of the analysis are the same, because planktonic heterotrophs generally increase with increasing food supply.

We surmise that the biomass distribution into autotrophic and heterotrophic compartments of the plankton along gradients of enrichment agrees with the macroscopic pattern suggested by ratio-dependent theory. Two aspects of the models of planktonic biomass should be considered in more detail. First, our data, as well as previous empirical models (Pace 1986; Cole and Caraco 1993) indicate that the log-log slopes of the relationships between autotrophic and heterotrophic biomass are generally well below one, and, therefore, the ratio of the two components varies systematically along gradients of enrichment in lakes. This trend applies to both total heterotrophic biomass and the biomasses of individual heterotrophic components (table 2). Second, these same empirical relationships are often characterized by relatively high intercepts (table 2), which suggests that in the absence of autotrophic biomass, there could still be measurable heterotrophic biomass. The microscopic assumptions about ratio-dependent foraging that underlie this theory are not necessarily supported by our data, and other mechanisms, such as heterogeneity within food levels (Hunter and Price 1992) and changes in the food supply (Power 1992), may determine similar patterns in biomass distribution. In the following sections we specifically explore some of the bottom-up processes that may result in the observed covariation of biomass along enrichment gradients and that may determine the low slopes and high intercepts that characterize the relationship between heterotrophic and autotrophic biomass in lakes.

\section{Resource Control of Planktonic Biomass}

From the perspective of resource control, the high relative heterotrophic biomass found in most oligotrophic lakes could be sustained by high algal turnover rates, by higher availability of primary production to heterotrophs, or by use of external sources of carbon. One paradigm of phytoplankton ecology holds that turnover rates of algae are highest in oligotrophic systems and decline along a gradient of increasing algal biomass (Odum 1971; Harris 1984). Increasing evidence suggests, however, that this pattern does not hold for freshwater phytoplankton. Comparative analyses indicate that phytoplankton production increases faster than chlorophyll concentrations (Smith 1979; del Giorgio and Peters 1993; Baines et al. 1994). Since chlorophyll concentration is a measure of phytoplankton biomass, phytoplankton production per unit biomass must also increase with increasing algal biomass.

Over a broad range of primary productivity in lakes, empirical evidence does not support the contention that the algal biomass of oligotrophic lakes turns over more rapidly than the biomass of eutrophic lakes (Baines et al. 1994). The decline in $H / A$ ratios in freshwater planktonic communities along gradients of increasing 
autotrophic biomass, therefore, may not be linked to a decrease in the turnover rate of the algal populations. A second factor that may influence the biomass distribution is a qualitative shift in the phytoplankton biomass. There is evidence that as algal biomass increases, the availability of this biomass to consumers may decrease (Watson and Kalff 1981; Watson and McCauley 1988; Malthus and Mitchell 1990), and this pattern has been invoked to explain the decline in the ratio of zooplankton to phytoplankton in lakes (Watson and McCauley 1988). Although we do not have detailed information on the size composition of phytoplankton in the Québec lakes we studied, the empirical models proposed by Watson and McCauley (1988) can be used to estimate the relative proportions of edible $(<35 \mu \mathrm{m})$ and inedible $(>35 \mu \mathrm{m})$ algae in these lakes, using TP as the independent variable. At a TP concentration of $5 \mu \mathrm{g} \mathrm{L}^{-1}$, which is the lower limit we encountered, edible algae would compose around $70 \%$ of the total phytoplankton biomass. At $40 \mu \mathrm{g} \mathrm{L}^{-1} \mathrm{TP}$, our upper limit, edible phytoplankton would compose $30 \%$ of the total algal biomass. Thus, the proportion of edible algae is likely to be half along the enrichment gradient in the Québec lakes, whereas the $H / A$ ratio declines fourfold along the same gradient (table 1). Phytoplankton-tozooplankton transfer may indeed be more efficient in oligotrophic waters, but the shift in algal size distribution is not large enough to explain the overall decline of the $H / A$ ratio along gradients of enrichment.

A third factor that may also strongly influence the biomass distribution is dissolved organic carbon. Lake bacterioplankton use dissolved organic carbon: a portion is respired, and the remainder is converted into biomass. This biomass is directly available to grazers, including mixotrophic algae, protozoans, ciliates, rotifers, and larger crustacean zooplankton. A large fraction of the total heterotrophic biomass in planktonic communities is composed of this detrital subsystem. Because planktonic grazers prey on both phytoplankton and smaller heterotrophs (Porter et al. 1988), these detrital carbon pathways are an integral part of pelagic food webs and cannot be treated separately (Sherr and Sherr 1988). Since the components of the detrital subsystems in pelagic food webs cannot be effectively excluded from the overall analysis, it is important to consider their sources of energy. The DOC pool in lakes is not only composed of products of algal excretion and lysis but also of organic carbon leached from littoral macrophytes and associated algae and from terrestrial vegetation within the drainage basin (Wetzel 1992). Most lakes have a sizable pool of DOC, ranging from 1.5 to over $20 \mathrm{mg} \mathrm{C}$ $\mathbf{L}^{-1}$, and much of this material is of allochthonous origin (Meili 1992). If phytoplankton is considered the sole food source for the plankton community, the dissolved organic matter derived from higher plants is ignored, and the energetic base of the pelagic community is underestimated. Since the heterotrophic detritivores and grazers are aggregated in the plankton, DOC should also be considered a component of the community food base.

The amount of DOC that is "labile" or readily available to the biota ranges from less than $5 \%$ to over $40 \%$ of the total DOC pool (Laird and Scavia 1990; Jones 1992; Tranvik 1992). In the 18 Québec lakes we sampled, DOC concentrations ranged from 2.5 to $7.5 \mathrm{mg} \mathrm{C} \mathrm{L}^{-1}$ (table 1). The total potential food base $(F)$ for consumers in these lakes can be estimated as the sum of phytoplankton stand- 
ing stock and the labile DOC. Algal biomass varies 16-fold in the Québec lakes, whereas the concentration of DOC varies less than threefold and is relatively high even in the most oligotrophic lakes (table 1). Thus, the addition of even a small labile fraction of DOC tends to dominate the estimated food base, particularly in oligotrophic lakes in which algal biomass is very low. If we assume that $5 \%$ of the DOC is biologically labile, the estimated food base $(F=$ algal $\mathrm{C}+5 \%$ DOC) would vary only fivefold among lakes. Heterotrophic biomass $(H)$ increases with $F$ with a $\log$-log slope not significantly different from unity (fig. $3 B$ ), and the $H / F$ ratio remains constant along a gradient of increasing plant carbon. This pattern remains unchanged if the labile DOC is assumed to be greater than $5 \%$.

The constancy of the ratio of heterotrophic biomass to food base suggests that heterotrophic biomass follows a resource gradient composed of both phytoplankton biomass and detrital DOC. This result is particularly interesting, because it suggests that the low slopes and high intercepts characteristic of empirical models that relate heterotrophic to autotrophic biomasses (table 2; see Pace 1986; Cole and Caraco 1993) may result from an incomplete description of the resource base rather than from trophic interactions within planktonic food webs. The high intercepts of heterotrophic versus autotrophic relationships probably reflect a greater influence of carbon subsidies in oligotrophic lakes (del Giorgio and Peters 1994). Because DOC concentrations are relatively high and homogenous among lakes, compared with the variation in chlorophyll and primary production, this organic carbon may become the major source of energy for the pelagic community where phytoplankton biomass is low. As phytoplankton carbon increasingly dominates the system along gradients of enrichment, the contribution of DOC to overall plankton metabolism probably declines. These high intercepts would tend to lower the slopes of the relationships between autotrophic and heterotrophic biomass in lakes, even if the carbon transfer efficiency from phytoplankton to heterotrophs remained constant across gradients of enrichment.

The constancy of the ratio of heterotrophic biomass to food base also suggests that most plankton communities are in fact characterized by a normal biomass pyramid, with a large resource base supporting successively smaller strata of consumers. This result is not apparent when the distribution of heterotrophic biomass is analyzed only in relation to phytoplankton, as we did in previous sections, where we concluded that many plankton communities are characterized by inverted biomass pyramids. It is only in the most eutrophic lakes, where phytoplankton overwhelmingly dominate the resource base, that the traditional paradigm of phytoplankton-based planktonic food webs apply. When applied to lakes, the underlying assumption of theories dealing with trophic interactions is that phytoplankton are the sole food source for planktonic consumers, so all processes should be scaled-down to phytoplankton biomass, regardless of whether prey- or ratio-dependent consumer foraging is hypothesized. Only the plankton of the more productive lakes conform to this assumption, whereas in most other lakes trophic theories would not apply in their current formulation.

The proportional increase in heterotrophic biomass with food supply is consistent with a basic resource control of plankton communities, regardless of the 
patterns in consumer foraging that operate in these communities. The pattern, however, is consistent with the macroscopic predictions of ratio-dependent theory, because consumer and resource biomass increase along productivity gradients with a constant ratio. It is difficult, however, to infer the underlying trophic function from the biomass distribution and therefore to test the microscopic assumptions about foraging that this theory makes. Theories that incorporate heterogeneity to prey dependence result in a similar macroscopic pattern of biomass distribution (Hunter and Price 1992). In the case of planktonic food webs, a substantial source of heterogeneity, in addition to temporal and spatial heterogeneity, would be the diversity of the food base itself. Productive systems with simplified and relatively homogenous phytoplankton-based food webs should tend to exhibit stronger top-down effects, consistent with prey-dependent consumer foraging. In unproductive systems, or systems receiving large energetic subsidies, these top-down effects may be buffered within a more diverse and heterogeneous resource base, in part supported by external inputs of organic carbon. This may explain, at least partially, the uneven and often unpredictable results of biomanipulation experiments in lakes and enclosures (DeMelo et al. 1992). What should be emphasized here is that most freshwater plankton communities are not the simple and self-contained systems idealized by many ecologists studying foodweb interactions.

The decline in planktonic $H / A$ ratios along a gradient of increasing primary production in lakes may be thus linked to a parallel decline in the importance of energetic subsidies to the plankton that occurs along the same productivity gradient. Food subsidies are not restricted to lakes, however, and are likely to be important in any habitat with a high edge-to-area ratio (Power 1992). Many riverine, estuarine, and coastal marine communities, for example, have been shown to be strongly dependent on external organic carbon inputs (Findlay et al. 1986; Hopkinson et al. 1989). In such cases, as in lakes, it is necessary to assess the entire resource base before any analysis of trophic interactions can effectively be made. The difficulty in determining resource subsidies in aquatic ecosystems is somewhat analogous to the problem of the spatial circumscription of communities in terrestrial systems. Consumer mobility beyond the spatial boundaries arbitrarily set for any given community may also be considered a variant of energetic subsidies to the system and could result in a distortion in the local patterns between autotrophic and heterotrophic biomass.

\section{Comparison with Other Systems}

To compare freshwater plankton with other systems, we used data on total auto- and heterotrophic biomass for marine and terrestrial systems (Whittaker and Likens 1973), forests (Reichle et al. 1973), and marine plankton (Holligan et al. 1984). Since biomass estimates for these terrestrial and aquatic systems are in $\mathrm{g} \mathrm{C} \mathrm{m}^{-2}$, we converted the volumetric biomass estimates for the Québec lakes into areal units by integrating over the depth of the epilimnion. This comparison also included those lake literature data that were originally presented in areal units.

There is a strong pattern of declining $H / A$ ratios with increasing plant biomass 


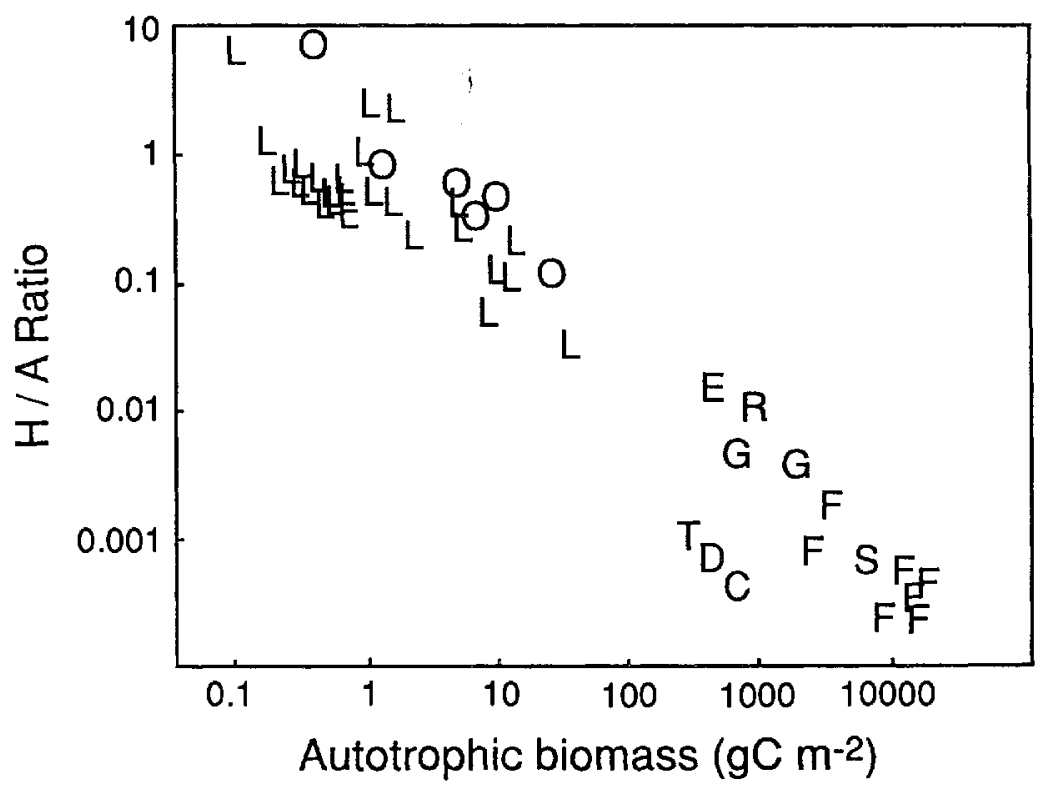

FIG. 4.-Ratio of heterotrophic to autotrophic biomass as a function of plant biomass for a wide range of systems. L, Lakes (literature data and Québec data from this study); $O$, oceanic plankton data extracted from Holligan et al. (1984) and Whittaker and Likens (1973); $F$, forests; $G$, grasslands; $D$, desert; $T$, tundra; $C$, cultivated land; $E$, estuaries; $S$, swamp; and $R$, reef extracted from Reichle et al. (1973) and Whittaker and Likens (1973).

across systems, from ultraoligotrophic lakes and oceans (autotrophic biomass $<$ $0.1 \mathrm{~g} \mathrm{C} \mathrm{m}^{-2}$ ) to tropical rain forests (plant biomass $>20 \mathrm{~kg} \mathrm{C} \mathrm{m}^{-2}$ ) (fig. 4). Heterotrophic to autotrophic biomass ratios decrease from $>1$ in extremely unproductive lakes and seas to less than $4.5 \times 10^{-4}$ in tropical forests. Overall, $H / A$ ratios decline as $A^{-0.7}$. Heterotrophic biomass, however, varies only 1.5 orders of magnitude across this range of systems, and the declining $H / A$ ratios are the result of the low slope that characterizes the $H$ versus $A$ relationship. The overall trend is consistent with the hypothesis that the heterotrophic standing crop per unit of autotrophic standing crop should be highest where plant biomass turns over most rapidly (O'Neill and DeAngelis 1981). The data on terrestrial autotrophic biomass, however, include both living and dead tissue, and in the case of forests, this results in a high overall biomass with an extremely low turnover rate. If only living tissue were considered, the $H / A$ ratios of terrestrial systems, particularly of forests, would be higher and probably somewhat closer to those measured in aquatic systems.

\section{SUMMARY}

Our results indicate that the ratio of total heterotrophic to autotrophic biomass in freshwater plankton communities declines systematically along gradients of increasing phytoplankton biomass. Marine plankton exhibit the same trend, and in the past, this trend has been associated to high turnover of oligotrophic phytoplankton. However, the pattern in freshwater $H / A$ ratios may not be linked to declining turnover rates of the autotrophic biomass along gradients of enrichment but rather to energetic subsidies. Our results suggest that total heterotrophic 
biomass follows a gradient of food supply, composed of algal biomass and detrital carbon as dissolved organic carbon. Because DOC concentrations are relatively high and homogenous among lakes, this organic carbon may become the major source of energy for the pelagic community in which phytoplankton biomass is low. The proportional increase in heterotrophic biomass with food supply is consistent with a basic resource control of plankton communities and also with the macroscopic predictions of ratio-dependent theory. It is difficult, however, to assess the microscopic assumptions about foraging that this theory makes from the observed biomass distribution. It is postulated that the degree of heterogeneity in the composition of the food base is an important factor determining the strength of top-down control in planktonic food webs. In the more productive lakes the food base is dominated by phytoplankton and is, therefore, more homogenous. In unproductive lakes and also in humic lakes, in which external carbon input is more important, the food base is more diversified and therefore more heterogeneous. Top-down effects and trophic cascades are more likely to be buffered in these systems.

Quantification of patterns in biomass distribution on a broader scale is limited by the lack of comparable data for terrestrial ecosystems. Our analysis, based on a rather small data set, indicates a systematic decline in the relative contribution of heterotrophic biomass as plant biomass increases from pelagic to forest ecosystems. More data on total auto- and heterotrophic biomass for terrestrial and marine systems are needed to further these comparisons. In terrestrial systems, plant biomass and primary production may be appropriate indicators of the community food base. In most lakes, however, scaling plankton processes to autotrophic production or biomass is inappropriate, because it ignores much of the energetic base of the community. Such incomplete scaling may result in patterns that could be misinterpreted as top-down control within planktonic communities. This warning extends to food web studies in general, because the risk of underestimating the resource base is not restricted to freshwater plankton communities.

\section{ACKNOWLEDGMENTS}

We thank R. H. Peters, H. Cyr, D. Tilman, and several anonymous referees for their valuable comments on the manuscript; and A. Simons, S. Clinton, and M. Schallenberg for their assistance in the field. This research was supported by Natural Sciences and Engineering Research Council of Canada grants, a Spanish government postdoctoral fellowship to J.M.G., and a Vineberg Fellowship to P.A.G.

Arditi, R., L. R. Ginzburg, and H. R. Akçakaya. 1991. Variations in planktonic densities in lakes: a case for ratio-dependent predation models. American Naturalist 138:1287-1296.

Baines, S. B., M. L. Pace, and D. M. Karl. 1994. Why does the relationship between sinking flux and planktonic primary production differ between lakes and oceans? Limnology and Oceanography 39:213-226. 
Bjørnsen, P. K. 1986. Automatic determination of bacterioplankton biomass by image analysis. Applied and Environmental Microbiology 51:1199-1204.

Børsheim, K. Y., and G. Bratbak. 1987. Cell volume to cell carbon conversion factors for a bacterivorous Monas sp. enriched from seawater. Marine Ecology Progress Series 36:171-175.

Carpenter, S. R., and J. F. Kitchell. 1988. Consumer control of lake productivity. BioScience 38: $764-769$.

Cole, J. J., and N. F. Caraco. 1993. The pelagic microbial food web of oligotrophic lakes. Pages 101-111 in T. E. Ford, ed. Aquatic microbiology. Blackwell Scientific, London.

del Giorgio, P. A. 1994. Heterotrophy in lake plankton. Ph.D diss. McGill University, Montreal.

del Giorgio, P. A., and R. H. Peters. 1993. The balance between phytoplankton production and plankton respiration in lakes. Canadian Journal of Fisheries and Aquatic Sciences 50: 282-289.

- 1994. Patterns in planktonic P/R ratios in lakes: influence of lake trophy and dissolved organic carbon. Limnology and Oceanography 34:772-787.

DeMelo, R., R. France, and D. J. McQueen. 1992. Biomanipulation: hit or myth? Limnology and Oceanography 37:192-207.

Elton, C. 1927. Animal ecology. Macmillan, New York.

Findlay, S., L. Carlough, M. T. Crocker, H. K. Gill, J. L. Meyer, and P. J. Phillip. 1986. Bacterial growth on macrophyte leachate and the fate of bacterial production. Limnology and Oceanography 31:1335-1341.

Flynn, K. J. 1988. The concept of "primary production"' in aquatic ccology. Limnology and Occanography 33:1215-1216.

Fretwell, S. D. 1987. Food chain dynamics: the central theory of ecology? Oikos 50:291-301.

Gates, M. A., A. Rogerson, and J. Berger. 1982. Dry to wet biomass conversion constant for Tetrahymena elliotti (Ciliophora, Protozoa). Oecologia (Berlin) 55:145-148.

Ginzburg, L. R., and H. R. Akçakaya. 1992. Consequences of ratio-dependent predation for steadystate properties of ecosystems. Ecology 73:1536-1543.

Harris, G. P. 1984. Phytoplankton productivity and growth measurements: past, present and future. Journal of Plankton Research 6:219-237.

Holligan, P. M., R. P. Harris, R. C. Newell, D. S. Harbour, R. N. Head, E. A. S. Linley, M. I. Lucas, P. R. G. Tranter, and C. M. Weekley. 1984. Vertical distribution and partitioning of organic carbon in mixed, frontal and stratified waters of the English Channel. Marine Ecology Progress Series 14:111-127.

Hopkinson, C. S., B. Sherr, and W. J. Wiebe. 1989. Size fractioned metabolism of coastal microbial plankton. Marine Ecology Progress Series 51:155-166.

Hunter, M. D., and P. W. Price. 1992. Playing chutes and ladders: heterogeneity and the relative roles of bottom-up and top-down forces in natural communities. Ecology 73:724-732.

Hutchinson, G. E. 1978. An introduction to population ecology. Yale University Press, New Haven, Conn.

Jones, R. I. 1992. The influence of humic substances on lacustrine planktonic food chains. Hydrobiologia 229:73-91.

Laird, G. A., and D. Scavia. 1990. Distribution of labile dissolved organic carbon in lake Michigan. Limnology and Oceanography 35:443-447.

Malthus, T. J., and S. F. Mitchell. 1990. On the occurrence, causes and potential consequences of low zooplankton to phytoplankton ratios in New Zealand lakes. Freshwater Biology 22:383-394.

McCauley, E. 1984. The estimation of the abundance and biomass of zooplankton samples. Pages 228-265 in J. A. Downing and F. Rigler, eds. A manual on methods for the assessment of secondary productivity in fresh waters. International Biological Program handbook 17. Blackwell Scientific, Oxford.

McCauley, E., W. W. Murdoch, and S. Watson. 1988. Simple models and variation in plankton densities among lakes. American Naturalist 132:383-403.

Meili, M. 1992. Sources, concentrations and characteristics of organic matter in softwater lakes and streams of the Swedish forest region. Hydrobiologia 229:23-41.

Mittelbach, G. G., C. W. Osenberg, and M. A. Leibold. 1988. Trophic relations and ontogenic 
niche shifts in aquatic ecosystems. Pages 219-235 in B. Ebenman and L. Persson, eds. Size-structured populations. Springer, Berlin.

Odum, E. P. 1971. Fundamentals of ecology. Saunders, New York.

OECD (Organization for Economic Cooperation and Development). 1980. OECD eutrophication program, alpine lakes. Swiss Federal Institute for Water Resources and Water Pollution Control, Dübendorf.

Oksanen, L., S. D. Fretwell, J. Arruda, and P. Niemela. 1981. Exploitation ecosystems in gradients of primary productivity. American Naturalist 118:240-261.

O'Neill, R. V. 1976. Ecosystem persistence and heterotrophic regulation. Ecology 57:1244-1253.

O'Neill, R. V., and D. L. DeAngelis. 1981. Comparative productivity and biomass relations of forest ecosystems. Pages 411-449 in D. E. Reichle, ed. Dynamic properties of forest ecosystems. Cambridge University Press, Cambridge.

Pace, M. L. 1986. An empirical analysis of zooplankton community size-structure across lake trophic gradients. Limnology and Oceanography 31:45-55.

Porter, K. G., H. Paerl, R. Hodson, M. Pace, J. Priscu, B. Riemann, D. Scavia, and J. Stockner. 1988. Microbial interactions in lake food webs. Pages 209-227 in S. R. Carpenter, ed. Complex interactions in lake communities. Springer, New York.

Power, M. E. 1992. Top-down and bottom-up forces in food webs: do plants have primacy? Ecology 73:733-746.

Prairie, Y. T., and D. F. Bird. 1989. Some misconceptions about the spurious correlation problem in the ccological litcraturc. Occologia (Bcrlin) 81:285-288.

Reichle, D. E., B. E. Dinger, N. T. Edwards, W. F. Harris, and P. Sollins. 1973. Carbon flow and storage in a forest ecosystem. Pages 345-365 in G. M. Woodwell and E. V. Pecan, eds. Carbon and the biosphere. AEC symposium series 30. U.S. Atomic Energy Commission, Washington, D.C.

Ricker, W. E. 1973. Linear regression in fishery research. Journal of the Fisheries Research Board of Canada 30:409-434.

Ricklefs, R. E. 1979. Ecology. 2d ed. Chiron, New York.

Sherr, E. B., and B. F. Sherr. 1988. Role of microbes in pelagic food webs: a revised concept. Limnology and Oceanography 33:1225-1227.

Smith, V. H. 1979. Nutrient dependence of primary productivity in lakes. Limnology and Oceanography 24:1051-1064.

Swift, M. J., O. W. Heal, and J. M. Anderson. 1979. Decomposition in terrestrial ecosystems. Studies in terrestrial ecosystems 5. Blackwell Scientific, Oxford.

Tranvik, L. J. 1992. Allochthonous dissolved organic matter as an energy source for pelagic bacteria and the concept of the microbial loop. Hydrobiologia 229:107-114.

Vörös, L., and J. Padisàk. 1991. Phytoplankton biomass and chlorophyll- $a$ in some shallow lakes in central Europe. Hydrobiologia 215:111-119.

Watson, S., and J. Kalff. 1981. Relationships between nanoplankton and lake trophic status. Canadian Journal of Fisheries and Aquatic Sciences 38:960-967.

Watson, S., and E. McCauley. 1988. Contrasting patterns of net- and nanoplankton production and biomass among lakes. Canadian Journal of Fisheries and Aquatic Sciences 49:915-920.

Wetzel, R. G. 1983. Limnology. 2d ed. Saunders, Philadelphia.

1992. Gradient-dominated ecosystems: sources and regulatory functions of organic matter in freshwater ecosystems. Hydrobiologia 229:181-198.

White, E., G. Payne, and S. Pickmere. 1988. A limitation to the usefulness of chlorophyll as a biomass indicator in eutrophication studies. Verhandlungen der Internationale Vereinigung Limnologie 23:598-601.

Whittaker, R. H. 1975. Communities and ecosystems. 2d ed. Macmillan, New York.

Whittaker, R. H., and G. E. Likens. 1973. Carbon in the biota. Pages 281-300 in G. M. Woodwell, and E. Pecan, eds. Carbon in the biota. AEC symposium series 30. U.S. Atomic Energy Commission, Washington, D.C.

Wilkinson, L. 1987. SYSTAT: the system for statistics. SYSTAT, Evanston, Ill. 